This item was submitted to Loughborough's Research Repository by the author.

Items in Figshare are protected by copyright, with all rights reserved, unless otherwise indicated.

\title{
Youth employment in a globalising world
}

PLEASE CITE THE PUBLISHED VERSION

http://dx.doi.org/10.3828/idpr.2013.7

\section{PUBLISHER}

(C) Liverpool University Press

\section{VERSION}

AM (Accepted Manuscript)

\section{PUBLISHER STATEMENT}

This work is made available according to the conditions of the Creative Commons Attribution-NonCommercialNoDerivatives 4.0 International (CC BY-NC-ND 4.0) licence. Full details of this licence are available at: https://creativecommons.org/licenses/by-nc-nd/4.0/

\section{LICENCE}

CC BY-NC-ND 4.0

\section{REPOSITORY RECORD}

Gough, Katherine V., Thilde Langevang, and George Owusu. 2019. "Youth Employment in a Globalising World". figshare. https://hdl.handle.net/2134/20614. 


\title{
Youth employment in a globalising world
}

\author{
Katherine V. Gough, Thilde Langevang and George Owusu
}

\begin{abstract}
Young people in the global South are seeking employment opportunities in challenging economic and social environments. This paper provides an overview of current debates regarding youth employment highlighting conceptualizations of youth and (un)employment, emerging youth employment trends, and the nature of policies introduced to tackle youth (un)employment. It provides an overview of the six papers that make up this special issue and shows how highlighting the complexities and diversities of youth employment strategies in sub-Saharan Africa, provides valuable lessons both for enhancing current conceptualisations and theorization of youth employment and in terms of related policy instruments.
\end{abstract}

\section{Introduction}

Young people in the global South are growing up in challenging social and economic environments. Economic restructuring and the transformation of labour markets have resulted in limited employment opportunities with the youth being especially affected. Although some young people are able to gain employment in the formal economy, especially in growing sectors such as IT and tourism, many have to create jobs for themselves. Rates of unemployment and underemployment are especially high for young people, which present challenges not only for the youth themselves but also for their families and society in general. There are increasing concerns that large sections of young people are being marginalized and excluded from employment and subsequently the status of adulthood. It is widely believed, though not entirely substantiated, that lack of employment can cause idleness and frustration among young people, which in turn can result in risky behaviour and involvement in crime, organised violence and protests (Garcia and Fares, 2008; World Bank, 2007; World Bank, 2013).

Despite this rather bleak picture, many young people do manage to gain employment, either working for others or more commonly setting up their own enterprises. This often requires a degree of entrepreneurship as the competition is fierce and the economic climate challenging (Langevang and Gough, 2012; Langevang et al., 2012). Against the odds, many young people in the global South hang onto the possibility of improving their lives through working and achieving social mobility (Gough, 2008). They engage in various strategies including: extending their formal education and gaining new skills, setting up their own businesses, forming networks and alliances, and migrating in search of new opportunities. Some of these strategies result in success whereas others fail causing increased disillusionment.

The issue of youth employment remains one of the major challenges for governments and is a key issue of concern for many development partners. Policy initiatives, however, tend to focus on formal employment and education, ignoring less formal means of meeting youth 
employment and learning needs, and overlook the degree to which young people are already economically active in the informal sector. Some institutions have initiated programmes that aim to encourage entrepreneurship among youth but little is known about how young people become entrepreneurs or how they can best be supported to gain employment (Chigunta et al., 2005). There is thus a need to generate a better understanding of how young people are managing to find or create employment, the opportunities and constraints that they face, and how they can best be supported.

The papers in this special issue of International Development Planning Review seek to make a contribution to our knowledge of the diverse experiences of young people in the global South in their attempts to obtain gainful employment, and the impacts of policies introduced to support them. Although the call for papers invited contributions from across the global South, all the abstracts that were submitted specialised on youth in sub-Saharan Africa. Consequently, the 6 papers in this special issue all focus on young people in one or more countries in sub-Saharan Africa spanning 11 countries in West, East and Southern Africa. As each paper includes, to a greater or lesser extent, a consideration of policies and programmes introduced to support youth employment in specific contexts, the collection as a whole makes an important contribution to our understanding of the challenges young people and policy makers face in generating youth employment.

The rest of this paper provides an introduction to a number of the key themes that are addressed in more detail in specific papers in the collection. It starts by conceptualizing youth and introducing the key approaches to studies of youth which may not be known to many readers of this journal. It then focuses on youth employment in the global South highlighting the difficulties faced in conceptualizing (un)employment, key educational issues, and the differences and links between income-earning opportunities in rural and urban areas. Finally, this introduction outlines key policy dimensions on youth employment which are developed further in the papers. The papers which make up this special issue are introduced at appropriate junctures and then summarized at the end.

\section{Conceptualizing and researching youth}

Youth is a widely debated concept. The most common way of defining youth is using chronological age, the most often used being the United Nations definition that categorizes youth as 15-24 year olds. Definitions adopted by other organizations and national governments vary widely, however, and many African countries define youth in very expansive terms with the upper ceiling pushed into the mid-thirties (Chigunta, 2013). Clearly youth is more than an age-bracket and various disciplines with differing traditions, theories and methodologies have contributed to discussions of the conceptualization of youth. Two perspectives which have dominated the debates are the life stage or youth transitions perspective, and the youth culture perspective (Christiansen et al., 2006, MacDonald et al, 2001).

Life stage and youth transitions studies approach youth as a distinct stage between childhood (characterized by dependence and immaturity) and adulthood (characterized by independence and maturity). Youth is seen as a stage through which people pass in order to become mature and independent adults (Skelton 2002). Transitions studies, however, have been criticized for being incapable of grasping young people's complex life paths in times of rapid socioeconomic change, and for reducing youth to a transitory state of becoming 'rather than a recognized stage in its own right with distinctive experiences and issues' (Skelton 2002, p. 103). Furthermore, the changes that have traditionally been associated with growing up, such 
as finding a job, leaving home, getting married and becoming a parent, may occur simultaneously or not at all and many of them are reversible (Johnson-Hanks, 2002; Valentine 2002). This is especially the case in the global South where rather than passing through neat and linear life stages young people traverse back and forth between fluid boundaries of time and place specific notions of childhood, youth and adulthood (Burgess, 2005; Christiansen et al. 2006; Honwana and de Boeck, 2005; Johnson-Hanks, 2002; Langevang, 2008; van Blerk, 2008).

Whereas life stage approaches focus on young people's transitions to adulthood, the cultural approach to youth focuses on the here-and-now lived experiences of young people. From this perspective youth is seen as a socially and culturally demarcated group who have distinctive views and experiences, with a key focus being young people's sub-cultures and styles. Although it is important to recognise that in different cultures youth is defined, very differently, the approach has been criticized for having a tendency to focus on young people's agency, often in isolation from the surrounding society, and on youth as deviant, spectacular and male (Valentine et al., 1998). Furthermore, studies of youth cultures have been overtly dominated by research in Northern contexts, especially Britain and the US. As Christiansen et al. (2006) argue, however, the bifurcation of youth studies into a transitions and a cultural approach is unnecessary and the two can be usefully combined. Understanding the lives of young people 'entails balancing our analysis between the ways young people see and interpret the world and the ways they are positioned in it as part of families and societies' (Christiansen et al., 2006, p. XX). This requires a simultaneous focus on being and becoming, 'illuminating how youth are able to move, what they seek to move towards and the ways external forces seek to shape their movements' (Christiansen et al., 2006, p. XX). It is in this vein that most of the papers in this special issue are written.

The last decade has seen an upsurge in research which has documented the diversity and multiplicity of young people's trajectories and lived experiences in a range of contexts in the global South (Ansell et al., 2011; Burgess, 2005; Camfield, 2011; Christiansen et al., 2006; Esson, 2013; Honwana and De Boeck, 2005; Jeffrey 2010; van Blerk 2008). As this research highlights, young people's lived experiences vary between places according to lines of difference including gender, ethnicity, socio-economic status and education etc. Drawing on the concept of intersectionality, Hajdu et al. (2013, this issue) show how young people in Malawi and Lesotho are both helped and constrained by various combinations of their gender, age, social status, educational level and marital status in relation to gaining access to livelihoods. Similarly, Doh et al. (2013, this issue) show how the socio-cultural context of ethnicity, gender stereotypes and perceptions, either independently or in combination, influence the skills preferences of young people in Ghana.

\section{Youth employment in the global South}

Employment has been central to the study of youth, especially in youth transition studies in the global North as transition into full employment is typically seen as a key entry point into adulthood. When transitions approaches first emerged in the 1980s in the UK, school-to-work transitions were the primary focus due to structural changes in the labour market and high rates of youth unemployment. Indeed, the issue of youth (un)employment tends to arise particularly in times of economic adversity, as illustrated by the current global economic crisis, since youth unemployment increases at a faster pace than overall unemployment. In the words of the ILO (2011), 
"Of the world's estimated 211 million unemployed people in 2009, nearly 40 per cent - or about 81 million - were between 15 and 24 years of age. In many countries, this grim unemployment picture is darkened further by the large number of youth engaged in poor quality and low paid jobs with intermittent and insecure work arrangements, including in the informal economy”.

The terms employment and un-/underemployment, however, are tricky concepts when applied in the global South hence any such figures have to be treated with caution. Defining the exact boundaries of employment and unemployment is fraught with difficulties; as Izzi (2013, this issue) argues, defining and measuring levels of unemployment is complicated as unemployment is 'difficult to measure, track over time and compare across space'. This is especially the case in economies characterised by a large informal sector where work is often irregular, insecure, casual and precarious (Bunnell and Harris, 2012). Recently, the African Economic Outlook (2012; italics in original) has suggested that a focus on 'unemployment' rates in Africa makes little sense as,

"Among the poor, few can afford not to be employed. Instead, underemployment, vulnerable employment and working poverty are widespread. Focusing on the unemployment rate fails to take into account this reality. It implicitly assumes that those in work are materially better off than the unemployed. In most African countries, however, this assumption does not hold. In fact, the unemployed are less likely to suffer from poverty than many self-employed or underemployed.'

Moreover, because unemployment is often defined as those who are actively seeking work, discouraged young people who have given up looking for work but are ready to work are excluded from unemployment figures.

Young people are much more likely to be unemployed than older adults; according to the World Development Report 2013, entitled simply 'Jobs', unemployment rates for youth are usually between two and three times the overall unemployment rate (World Bank, 2013). Issues of youth employment and unemployment have recently become key concerns in Africa, which has the youngest population in the world. There are an estimated almost 200 million people aged between 15 and 24 on the African continent which it is expected will double by 2045 (African Economic Outlook, 2012). The large numbers of young people joining the labour force every year are putting great pressure on already crowded job markets. However, at a time when countries in the global North are undergoing economic crisis and recession, many countries in Africa are recording high levels of growth; between 2001 and 2010, six of the world's ten fastest-growing economies were in sub-Saharan Africa (African Economic Outlook, 2012). As much of this growth derives from primary commodity production and extractive industries, it generates little employment resulting in 'jobless growth’ (World Bank, 2013).

One of the key issues linked to youth (un)employment is education. Due to a policy emphasis on education during the last decade, connected to the Millennium Development Goals, more children are enrolling in primary and secondary education than ever before. Based on current trends it is predicted that 59 percent of 20-24 year olds will have had secondary education in 2030, compared to 42 percent today (African Economic Outlook 2012). While this is a positive development, such numbers say little about what kind of knowledge and skills young people acquire or whether they are able to use these skills in the labour market. Increased educational levels are not being met by corresponding employment opportunities and 
secondary school and university graduates are amongst those most likely to be unemployed (Jeffrey, 2010). As Darkwah (2013, this issue) convincingly demonstrates, even young people who pursue education initiatives to enable them to enter the booming oil and gas industry in Ghana are failing to obtain the promised employment at the end of their training. Many young people in Ghana and elsewhere continue to turn to informal apprenticeship systems in order to learn practical skills which better equip them for the marketplace (Doh et al. 2013, this issue; Langevang and Gough, 2012). Consequently, a considerable element of education and the equipping of young people with skills is taking place through informal means and outside of state regulation.

In rural areas of the global South, young people are typically reported to be turning their backs on farming, seeking either non-farm employment or migrating to urban areas (White, 2012). As Sumberg et al. (2012: 2) argue, the 'problem' of young people and agriculture is typically framed from a perspective of either 'youth in peril' or 'agriculture in peril', resulting in oversimplified pictures of either 'agriculture as the saviour of young people' or 'young people as the saviour of agriculture'. Nevertheless, as Hajdu et al. (2013, this issue) note, rural youth in the global South still rely mainly on agriculture for their livelihoods. However, as Kristensen and Birch-Thomsen (2013, this issue) illustrate, rural youth in different places are following diverse employment trajectories; whilst rural youth in Uganda are migrating in considerable numbers to urban areas, in Zambia young people are choosing to stay in, and are even returning to, rural areas where they are successfully combining agriculture with alternative livelihood activities. This ties in with Potts' (2012) claims that some countries in sub-Saharan Africa, including Zambia, are experiencing counterurbanisation.

In urban areas of the global South, as the chances of young people obtaining work in the formal economy are increasingly slim, many are creating their own employment becoming self-employed 'entrepreneurs'. Little is known though about young people's entrepreneurship activities, how well-equipped young would-be entrepreneurs are, or the types of livelihoods young entrepreneurs are able to generate (Chigunta et al., 2005). Entrepreneurship itself is a complex concept that is difficult to pin down with ongoing debate whether any business activity should be classified as entrepreneurship or if the label entrepreneur should be reserved for those who introduce radical innovations (Hanson, 2009; Langevang et al., 2012). As Jeffrey and Dyson (2013: 1) highlight, there are 'ideological risks attached to celebrations of entrepreneurialism' since this can result in state non-investment in core services based on the belief that young people can 'pull themselves up by their own bootstraps'. Furthermore, as Thorsen (2013, this issue) shows, although many young people seeking work in urban areas are highly resourceful drawing in particular on kinship relations, their incomegenerating activities are unpredictable and unstable.

Clearly, places do not neatly fall into the categories rural and urban, rather being located along a continuum between the two. Consequently, many young people combine a range of activities in their attempts to generate livelihoods sometimes moving between places according to where they consider their best options to be. Whilst for some young people a move may be permanent, many oscillate between places in response to education and employment opportunities, family obligations, and living preferences (Gough 2008; Olwig and Gough, 2012; Porter et al., 2010; Porter et al., 2011; Skelton and Gough, 2013). Several of the papers in this special issue, in particular Thorsen (2013) and Kristensen and BirchThomsen (2013) add to our knowledge of the interconnections of young people between rural and urban areas in search of employment opportunities. 


\section{Policies to support youth employment in the global South}

Governments in the global South are well aware that the level of employment of an economy is a good indicator of the health of the economy as well as the overall general well-being of the population. Youth unemployment is considered not only to impact negatively on young people and their households, but also on the wider economy through reduced outputs, tax revenues and wastage of human capital (Garcia and Fares, 2008), hence for policy-makers worldwide youth employment is high on their list of priorities (World Bank, 2007). The question of youth unemployment and underemployment, however, cannot be abstracted from broader labour questions and the challenges of promoting economic growth.

Policy interventions to generate youth employment tend to adopt one of three approaches: increasing economic growth to broaden opportunities for employment; increasing youth capabilities through education and skills training at all levels; and programmatic interventions involving specific tailored-made projects to promote youth employment (ISSER, 2010). The rationale behind programmatic interventions to promote youth employment is that youth differ from their non-youth counterparts as due to their age they have relatively little experience, limited capital outlay, restricted social networks and low status. Thus policies are typically introduced to strengthen or create labour market institutions that help young people access jobs, promote entrepreneurship, and direct training of the youth toward market needs (ISSER, 2010). Although there is considerable rhetoric regarding the participation of young people in policy processes, in practice they tend to be treated as passive clients with a limited ability to shape their own destinies (Bordonaro and Payne, 2012; te Lintelo, 2012; Sunberg et al., 2012). Furthermore, young people are typically treated as a homogenous group without regard to their differing characteristics or their place in wider social relations (see Izzi 2013, this issue), which contributes to the relative ineffectiveness of many youth employment policies.

Many African countries have drawn up National Youth Policies (NYPs), one of the key aims of which is to support youth employment. The overall message that young people are receiving from their governments, as well as from local and international organizations, is that they should become 'job creators' rather than 'job seekers' by setting up their own enterprises (Chigunta et al., 2005, Langevang et al., 2012). Numerous policies and programmes exist to promote youth entrepreneurship despite very little being known about the likelihood of success of these programmes. As Izzi (2013, this issue) aptly demonstrates in the context of post-conflict societies, youth employment projects are falling short of their expectations. Similarly, the papers in this special issue by Kristensen and Birch-Thomsen (2013), Hadju et al. (2013) and Darkwa (2013) highlight how policies are either missing their targets, making misguided attempts to target the most vulnerable, or are inadequate to support the youth in their search for employment.

\section{The collection}

The six papers in this special issue focus on a wide range of young people seeking employment opportunities in varying contexts within differing countries in sub-Saharan Africa and on the effectiveness of policies introduced to support them. To round off this introduction, a brief summary of each of the papers is presented here.

The paper by Valeria Izzi starts off the collection with a valuable piece highlighting the challenges of defining youth unemployment and of devising policies to reduce it. She illustrates how despite it being a common assumption, there is limited evidence of any direct linkage between youth unemployment and violence. Focusing in particular on youth in post- 
conflict societies, she highlights how although policies introduced to stimulate youth employment are laudable, only a minority of youth can be supported which can cause more harm than good, plus there is no evidence that the policies manage to create long-term stable jobs. Consequently she argues that the practice of using youth employment projects for peacebuilding is rooted in problematic assumptions and requires further research.

Drawing on Bourdieu's notion of 'blighted hope', in a fascinating paper Akosua Darkwah examines the experiences of young people following one of the training programmes that are mushrooming in Ghana to educate young people for the oil and gas industry. She convincingly demonstrates how these initiatives are merely serving to give young people the hope of accessing formal employment. This hope is unlikely to materialize for the majority of the trainees, many of whom are patiently waiting for their dreams to come true though with increasing frustration and embarrassment that their considerable investments have led to nothing. She concludes the paper by arguing that although hopefulness is a virtue, it is vital that the government introduces policies to improve the chances of trainees obtaining employment, and has some useful suggestions regarding what these could be.

Staying in Ghana, Daneil Doh, Ellen Borte-Doku Aryeetey and Paul Andoh focus on a different but very important aspect of the vocational education system, the informal apprenticeship system. Drawing on extensive qualitative data, they explore the reasons behind young people's choices of which apprenticeship to follow. They convincingly demonstrate the importance of family relations, and in particular the role of uncles and aunts, in the decision-making process. The financial situation within the home is another important contributing factor as the training costs and subsequent capital needed to set up in business vary considerably. They argue that the young people would benefit from a more formal guidance and counseling system regarding which skills training to undertake.

The subsequent paper by Flora Hajdu, Nicola Ansell, Elsbeth Robson and Lorraine van Blerk considers policies that are introduced in rural areas to improve young people's possibilities to access (self)employment. Drawing on qualititative data collected in Malawi and Lesotho, they illustrate the types of income-generating activities that young people engage in and the constraints they face. Drawing effectively on the concept of intersectionality, they demonstrate how livelihood outcomes are a complex interaction of individual characteristics and structural factors at national and global scales. Consequently, they are able to highlight the problems associated with targeting specific groups of young people and argue that resources would be better spent on improving rural livelihoods in general rather than on resource-consuming selection processes.

Similarly with a rural focus, and also drawing on data from two countries, in this case Uganda and Zambia, Soren Kristensen and Torben Birch-Thomsen explore the employment strategies of young people in four settlements. Through analyzing both quantitative and qualitative data they highlight how for all the young people agriculture forms a major source of livelihood which they often combine with other income-generating activities in order to increase their resilience. Interestingly, there is a clear difference between the migration strategies of the young people studied in Uganda and Zambia. Whereas a significant proportion of the Ugandan youth migrate to urban areas in search of employment opportunities, in Zambia the young people consider their employment prospects to be greater in the rural areas. This has important implications for policy makers who generally consider rural youth to be disinterested in farming. 
Finally, the collection is rounded off by a paper by Dorte Thorsen who explores the strategies of young people from rural areas seeking employment in urban areas, again illustrated using data from two countries, this time Burkina Faso and Cote D'Ivoire. Drawing on ethnographic research, she outlines in detail three biographies of young people originally from the Bisa region of Burkina Faso who have moved to Ougadougou and Abidjan. Her detailed analysis highlights the unpredictability of young people's work in the informal urban economy. The frequent mobility of the young people, and their ability to develop livelihoods stretched across multiple locations, has clear implications for policy makers who tend to characterize young people and being either rural or urban based and treat them as being fixed in specific locations.

Together these papers make an important contribution towards our knowledge of the complexities and diversities of youth employment strategies in sub-Saharan Africa. Furthermore, they provide valuable lessons both for enhancing current conceptualisations and theorization of youth employment and in terms of related policy instruments.

\section{Acknowledgements}

All three authors are part of the 'Youth and Employment: the role of Entrepreneurship in African Economies' (YEMP) research project supported by the Consultative Research Committee for Development Research under the Danish Ministry of Foreign Affairs (YEMP 09-059KU). The helpful comments on this introduction by David Simon are gratefully acknowledged. In addition, many thanks to Patrick Brereton at Liverpool University Press for his support and patience during the production of this special issue.

\section{References}

AFRICAN ECONOMIC OUTLOOK (2012), ‘Africa Economic Outlook Report 2012: Promoting youth employment', http://www.africaneconomicoutlook.org/en/ (accessed January 2013).

ANSELL, N., VAN BLERK, L., HAJDU, F., and ROBSON, E. (2011), 'Space, times, and critical moments: a relational time-space analysis of the impacts of AIDS on rural youth in Malawi and Lesotho', Environment and Planning A, 43, 525-544.

BORDONARO, L.I. and PAYNE, R. (2012) 'Ambiguous agency: critical perspectives on social interventions with children and youth in Africa', Children's Geographies, 10, 365-372.

BUNNELL, T. and HARRIS, A. (2012), 'Re-viewing informality: perspectives from urban Asia’, International Development Planning Review, 34, 339-347.

BURGESS, T. (2005), 'Introduction to youth and citizenship in East Africa', Africa Today, 51, vii-Xxiv.

CAMFIELD, L. (2011), 'From school to adulthood? Young people’s pathways through schooling in urban Ethiopia, European Journal of Development Research, 23, 679-694.

CHIGUNTA, F. (2012), The youth and labour market needs in Zambia, Final Report to British Council. 
CHIGUNTA, F., SCHNURR, J., JAMES-WILSON, D. and TORRES, V. (2005), 'Being 'Real' about Youth Entrepreneurship in Eastern and Southern Africa' (SEED Working Paper No. 72), Geneva: International Labour Organisation, 1-58.

CHRISTIANSEN, C., UTAS, M. and VIGH, H. E. (2006), 'Introduction: navigating youth, generating adulthood', in C. Christiansen, M. Utas and H. E. Vigh (eds.) Navigating Youth, Generating Adulthood, Uppsala, The Nordic Africa Institute, 9-28.

DARKWAH, A. K. (2013), 'Keeping hope alive: an analysis of training opportunities in the emerging oil and gas industry’, International Development Planning Review, 34, ??

DOH, D., ARYEETEY, E. B. D, and ANDOH, P. (2013), Choosing an apprenticeship: skills preferences among the youth, International Development Planning Review, 34, ??

DURHAM, D. (2000), 'Youth and the social imagination in Africa: introduction to parts 1 and 2', Anthropological Quarterly, 73, 113-20.

ESSON, J. (2013), 'A body and a dream: West African youth, mobility and football trafficking', University of London unpublished $\mathrm{PhD}$ thesis.

GARCIA, M. and FARES, J. (eds.) (2008), Youth in Africa's labor market, Washington, DC, World Bank Publications.

GOUGH, K. V. (2010), 'Continuity and adaptability of home-based enterprises: a longitudinal study from Accra, Ghana', International Development Planning Review, 32, 4570 .

GOUGH, K. V. (2008), 'Moving around': social and spatial mobility of youth in Lusaka', Geografiska Annaler, 90, 243-255.

HAJDU, F., ANSELL, N., ROBSON, E. and VAN BLERK, L. (2013), 'Rural young people's opportunities for employment and entrepreneurship in globalized southern Africa: the limitations of targeting policies', International Development Planning Review, 34, ??

HANSEN, K.T.H., DALSGAARD, A.L., GOUGH, K.V., MADSEN, U.A., VALENTIN, K. and WILDERMUTH, N. (2008), Youth and the City in the Global South: urban lives in Brazil, Vietnam and Zambia, Bloomington, Indiana University Press.

HANSON, S. (2009), ‘Changing places through women’s entrepreneurship’, Economic Geography, 85, 245-267.

HONWANA, A. and DE BOECK, F. (eds.) (2005), Makers and Breakers: Children and Youth in Postcolonial Africa, Oxford, James Currey.

ILO (INTRENATIONAL LABOUR ORGANISATION) (2011), 'Policy Options to Support Young Workers during Economic Recovery’ (ILO Policy Brief), Geneva, International Labour OrganiSation. 
ISSER (INSTITUTE OF STATISTICAL, SOCIAL AND ECONOMIC RESEARCH) (2011), 'The State of the Ghanaian Economy in 2009', Accra, Institute of Statistical, Social and Economic Research.

IZZI V. (2013), 'Just keeping them busy? Youth employment projects as a peacebuilding tool’, International Development Planning Review, 34, ??

JEFFREY, C. (2010), 'Timepass: Youth, class and time among unemployed men in India', American Ethnologist, 37, 465-481.

JEFFREY, C. AND DYSON, J. (2013) Zigzag capitalism: Youth entrepreneurship in the contemporary global South, Geoforum, http://dx.doi.org/10.1016/j.geoforum.2013.01.001

JOHNSON-HANKS, J. (2002), 'On the limits of life stages in ethnography: toward a theory of vital conjunctures, American Anthropologist, 104, 865- 880.

KRISTENSEN, S. and BIRCH-THOMSEN, T. (2013). 'Should I stay or should I go? Youth and rural employment in Uganda and Zambia’, International Development Planning Review, 34, ??

LANGEVANG, T. (2008), 'We are Managing!' Uncertain Paths to Respectable Adulthoods in Accra, Ghana’, Geoforum, 39, 2039-2047.

LANGEVANG, T. and GOUGH, K. V. (2012), 'Diverging pathways: young female employment and entrepreneurship in sub-Saharan Africa’, The Geographical Journal, 178, 242-252.

LANGEVANG, T., NAMATOVU, R. and DAWA, S. (2012), 'Beyond necessity and opportunity entrepreneurship: motivations and aspirations of young entrepreneurs in Uganda’, International Development Planning Review, 34, 242-252.

MACDONALD, R., MASON, P., SHILDRICK, T., WEBSTER, C., JOHNSTON, L., and RIDLEY, L. (2001), 'Snakes \& ladders: in defence of studies of youth transition', Sociological Research Online, 5.

OLWIG, M. F. and GOUGH, K. V. (2012), 'Basket weaving and social weaving: young Ghanaian artisans' mobilization of resources through mobility in times of climate change', Geoforum, http://dx.doi.org/10.1016/j.geoforum.2012.11.001 (accessed December 2012).

PORTER, G., HAMPSHIRE, K., ABANE, A., TANLE, A., ESIA-DONKOH, K., AAMOAKO-SAKYI, R. O., AGBLORTI, S. and OWUSU, S. A. (2011), 'Mobility, education and livelihood trajectories for young people in rural Ghana: a gender perspective'. Children's Geographies, 9, 395-410.

PORTER, G., HAMPSHIRE, K., ABANE, A., ROBSON, E., MUNTHALI, A., MASHIRI, M. and TANLE, A. (2010), 'Moving young lives: mobility, immobility and inter-generational tensions in urban Africa’, Geoforum, 41, 796-804.

POTTS, D. (2012), 'What do we know about urbanization in sub-Saharan Africa and does it matter?', International Development Planning Review, 34, v-xxi. 
SKELTON, T. (2002), 'Research on youth transitions: some critical interventions', in: M. CIESLIK and G. POLLOCK, G. (eds.), Young People in Risk Society: The Restructuring of Youth Identities and Transitions in Late Modernity, Aldershot, Ashgate, 100-116.

SKELTON, T. and GOUGH, K. V. (2013), 'Young people's im/mobile urban geographies: introduction, Urban Studies, 50, 455-466.

SUMBERG, J., ANYIDOHO, N. A., LEAVY, J., TE LINTELO, D. J. H. and WELLARD, K. (2012), 'Introduction: the young people and agriculture 'problem' in Africa', IDS Bulletin, 43, 1-8.

TE LINTELO, D. J. H. (2012), 'Young people in African (agricultural) policy processes? What national youth policies can tell us', IDS Bulletin, 43, 90-103.

THOMSON, R., BELL, R., HOLLAND, J., HENDERSON, S., MCGRELLIS, S. and SHARPE, S. (2002), 'Critical moments: choice, chance and opportunity in young people's narratives of transition’, Sociology, 36, 335-354.

THORSEN, D. (2009), 'From shackles to links in the chain. Theorising adolescent boys’ relocation in Burkina Faso’, Forum for Development Studies, 36, 81-107.

THORSEN, D. (2013), Weaving in and out of employment and self-employment: young rural migrants in the informal economies of Ouagadougou and Abidjan, International Development Planning Review, 34, ??

VALENTINE, G., SKELTON, T. and CHAMPERS, D. (1998), 'Cool places: an introduction to youth and youth cultures', in T. Skelton and G. Valentine (eds.), Cool places: Geographies of Youth Cultures, London, Routledge, 1-32.

VALENTINE, G. (2003), 'Boundary crossings: transitions from childhood to adulthood', Children's Geographies, 1, 37-52.

VAN BLERK, L. (2008), 'Poverty, migration and sex work: youth transitions in Ethiopia', Area, 40, 245-253.

WHITE, B. (2012), 'Agriculture and the generation problem: rural youth, employment and the future of farming', IDS Bulletin, 43, 9-19.

WORLD BANK (2007), 'World Development Report 2007: Development and the next generation', Washington, The World Bank.

WORLD BANK (2013), 'World Development Report 2013: Jobs’, Washington, The World Bank. 